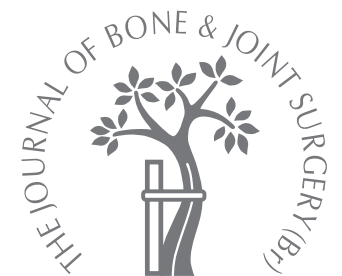

A. Ivkovic,

I. Boric,

N. Cicak

From Department of Orthopaedic Surgery, University of Zagreb, Zagreb, Croatia
A. Ivkovic, MD, Orthopaedic Surgery, Resident

N. Cicak, MD, PhD, Professor of Orthopaedic Surgery

Department of Orthopaedic Surgery

University of Zagreb, Salata 7, 10000 Zagreb, Croatia.

I. Boric, MD, MSc, Radiologist

Department of Radiology Children's Hospital Zagreb, Klaiceva 16, 10000 Zagreb, Croatia.

Correspondence should be sent to Dr A. Ivkovic; e-mail: aivkovic@inet.hr

(C)2007 British Editorial Society of Bone and Joint Surgery doi:10.1302/0301-620X.89B6. $18842 \$ 2.00$

$J$ Bone Joint Surg $[\mathrm{Br}]$ 2007:89-B:825-8. Received 31 October 2006; Accepted after revision 6 December 2006

\title{
One-stage operation for locked bilateral posterior dislocation of the shoulder
}

\begin{abstract}
A man of $\mathbf{5 2}$ years of age had a grand mal seizure. He presented to our unit three months later with irreducible bilateral posterior dislocation of the shoulder. CT scans revealed large compression defects on the anteromedial aspect of the heads of both humeri. The defect on the right side was of more than $\mathbf{5 0 \%}$ of the articular surface, and on the left side of $40 \%$. $\mathrm{He}$ was treated by a one-stage operation with a hemiarthroplasty on one side and reconstruction of the head by an osteochondral autograft on the other. Three years later the clinical and radiological results were excellent.
\end{abstract}

Less than $3 \%$ of dislocations of the shoulder are posterior and most are missed on initial examination. ${ }^{1-4}$ Bilateral posterior dislocation is even more rare, and of 30 patients attending our unit with posterior dislocation in only two was it bilateral. We present a patient with irreducible bilateral posterior dislocations treated by a one-stage operation involving hemiarthroplasty on the dominant side, and reconstruction of the humeral head by an osteochondral autograft on the other.

\section{Case report}

A 52-year-old man had a grand mal seizure while driving his car. He received immediate medical attention in a small hospital in another country and antiepileptic therapy was initiated. After three months he presented to our unit.

He had moderate pain in both shoulders, which were adducted and internally rotated (Fig. 1). Active and passive movements were limited and painful (Table I). There was no vascular or neurological abnormality in the upper limbs.

Standard radiographs revealed bilateral posterior dislocation with a large anteromedial impression in the right humeral head (Fig. 2). CT was used to assess the degree of involvement of the head, which was determined to be more than $50 \%$ of the articular surface on the right side (Fig. 3 ) and $40 \%$ on the left. Following Cicak's ${ }^{5}$ classification of defects of the humeral head, we decided to perform a hemiarthroplasty on the right and to use the excised segment for osteochondral autograft reconstruction on the left.
Through a standard deltopectoral approach the right shoulder was explored and, with difficulty, the dislocation was reduced. Inspection showed the impacted anteromedial defect of the humeral head to be greater than $50 \%$.

An osteotomy of the remaining humeral head was done and a hemiarthroplasty cemented in $20^{\circ}$ of retroversion. The left shoulder was approached in similar fashion. After reduction, the impacted anteromedial defect of around $40 \%$ was confirmed. The articular

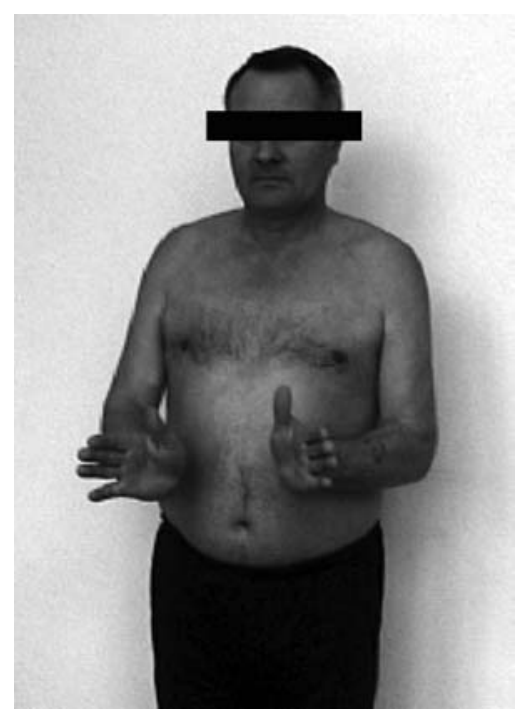

Fig. 1

Photograph showing classic posture of the patient with locked bilateral posterior dislocation. The arms are internally rotated, and the patient cannot achieve the neutral position because the humeral heads are fixed on the posterior glenoid rim. 
Table I. Pre- and post-operative ranges of movement

\begin{tabular}{|c|c|c|c|c|}
\hline & \multicolumn{2}{|c|}{ Right shoulder (hemiarthroplasty) } & \multicolumn{2}{|c|}{ Left shoulder (autograft) } \\
\hline & Pre-operative & Post-operative & Pre-operative & Post-operative \\
\hline Flexion $\left({ }^{\circ}\right)$ & 90 & 140 & 100 & 160 \\
\hline Abduction $\left({ }^{\circ}\right)$ & 30 & 90 & 35 & 110 \\
\hline Internal rotation $\left({ }^{\circ}\right)$ & Sacrum & L5 & Sacrum & L2 \\
\hline External rotation $\left({ }^{\circ}\right)$ & -20 & 45 & -20 & 65 \\
\hline
\end{tabular}

segment from the right shoulder was shaped into a well-fitting osteochondral autograft to reconstruct the defect (Fig. 4). Stable compression fixation was obtained using two $4.5 \mathrm{~mm}$ cancellous screws.

When followed up at three years, the left shoulder was generally painless with a range of movement of $160^{\circ}$ of flexion, $65^{\circ}$ of external rotation, internal rotation to L2, and $110^{\circ}$ of abduction. In the right shoulder he had occasional pain, especially after physical work. This side had approximately $140^{\circ}$ of flexion, $45^{\circ}$ of external rotation, internal rotation to L5 and $90^{\circ}$ of abduction (Fig. 5). The postoperative Constant score ${ }^{6}$ was 86 for the left and 55 for the right shoulder.

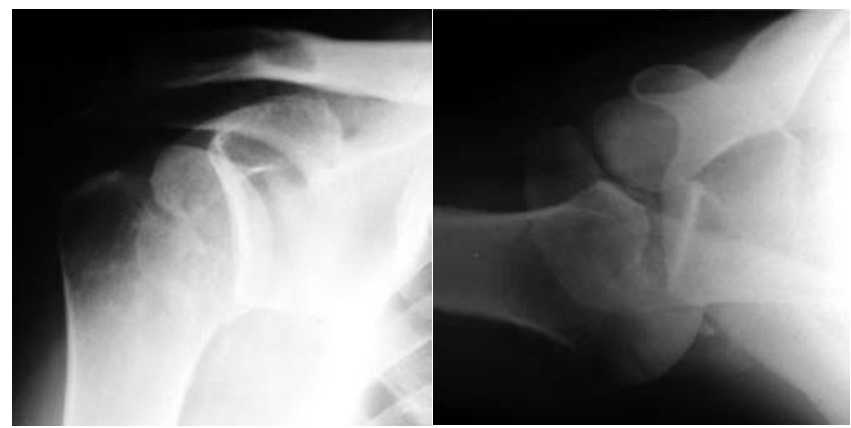

Fig. 2

Anteroposterior and axial radiographs of the right shoulder showing posterior dislocation.
The post-operative MRI and radiographs of the left shoulder showed good incorporation of the autograft with no evidence of osteonecrosis or osteoarthritis (Figs 6 and 7). Radiographs of the right shoulder showed a good position of the hemiarthroplasty and no sign of loosening. He remains very satisfied with his treatment and level of function.

\section{Discussion}

The rarity, mechanism and high rate of misdiagnosis of bilateral posterior dislocation of the shoulder are well documented. ${ }^{7-12}$ Important clinical features include fixed internal rotation, highlighted by an inability to externally rotate

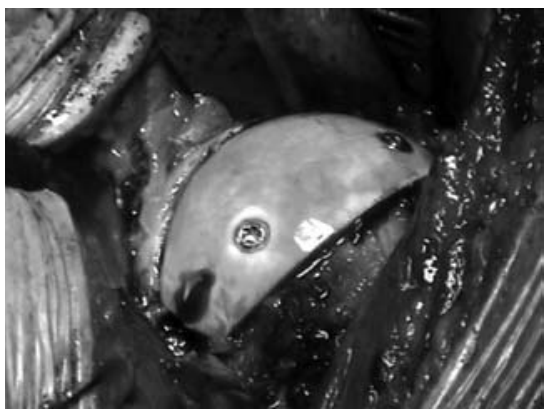

Fig. 4

Intra-operative view of the left shoulder showing a well-fitted osteochondral graft secured by two cancellous screws.

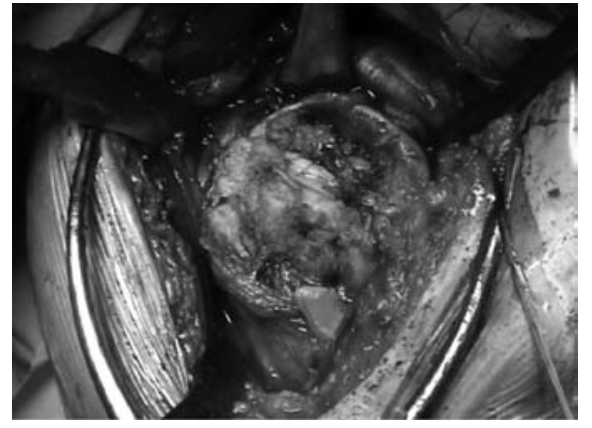

Fig. 3

Intra-operative view of the right shoulder demonstrating a large anteromedial defect greater than $50 \%$ of the articular surface. 


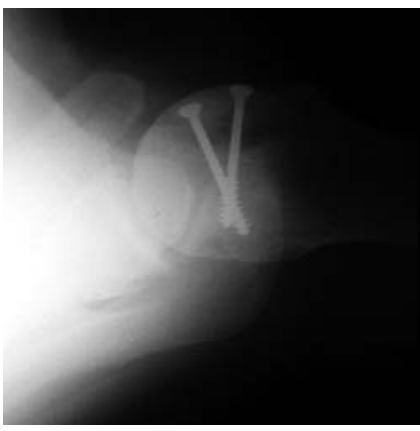

Fig. 6a

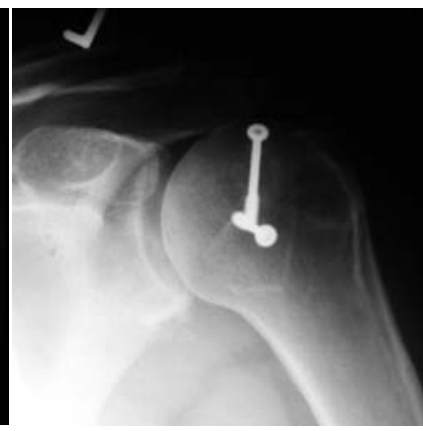

Fig. 6b
Radiographs of the left shoulder three years after operation.

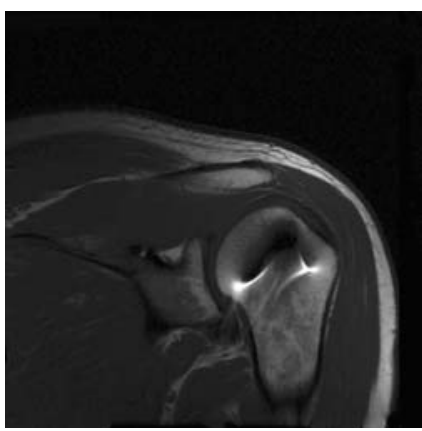

Fig. 7a

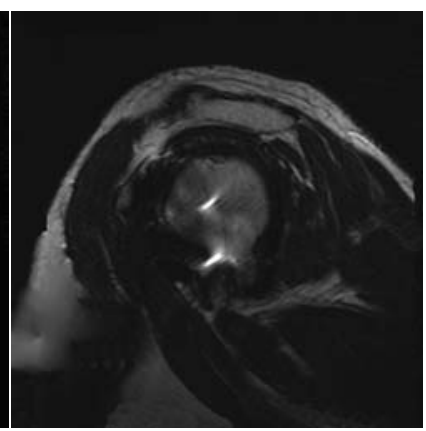

Fig. $7 b$
MR a) axial and b) coronal oblique SE, T1, WI and FST, T2, WI images of the left shoulder show normal signal intensity throughout the humeral head as a sign of good vitality. There is a small area of reactive subchondral sclerosis in the medial aspect of the humeral head. The artefact is caused by the screws.

the upper limbs when holding them with the shoulder flexed to $90^{\circ}$ and the elbow extended. ${ }^{13}$ A posterior prominence is usually palpable, the anterior shoulder is flattened and the coracoid process more prominent.

The diagnosis is usually confirmed by standard plain radiographs, the most important being the axillary view, which may be difficult to obtain because of pain and stiffness. In such cases a modified axillary lateral or lateral scapular view should be taken. ${ }^{14,15}$ CT scans are essential to evaluate damage to the humeral head and associated fractures, of the tuberosity, surgical neck and glenoid. ${ }^{16}$

The management of locked bilateral posterior dislocation is multifactorial and must be individually based and fully discussed with the patient. The main considerations are the size of the defect in the head, the duration of the dislocation, and the age and activity of the patient. A practical guide to treatment is based on the percentage size of the humeral impression fracture. ${ }^{5}$ Up to $25 \%$ damage to the articular surface can be treated by closed or open reduction augmented by subscapularis transfer if there is residual instability. ${ }^{4,17}$ For a defect between $25 \%$ and $50 \%$ of the articular surface, transfer of the lesser tuberosity, as described by Hawkins et al, ${ }^{2}$ can be undertaken. Alternatives include autograft and allograft reconstruction. ${ }^{18,19}$ Osteochondral grafts can be fixed with screws or bioabsorbable pins. We prefer metallic screws which allow better fixation with earlier and more vigorous rehabilitation. Defects greater than $50 \%$ of the articular surface should be treated with a surface replacement arthroplasty or a hemiarthroplasty. ${ }^{20-22}$ Although the former offers advantages, we did not have access to such implants.

The only literature which we could find on the subject was by Connor et $\mathrm{al}^{18}{ }^{18}$ who recommended hemiarthroplasty on one side and acute osteochondral autografting on the other. We too were reluctant to perform bilateral hemiarthroplasties because of the risk of inadequate function. The method which we have described is appropriate for bilateral dislocation, even when the articular defect is greater than $50 \%$ on both sides. The anatomical reconstruction should be performed on the dominant arm, allowing better function of that limb. If this fails, surface replacement or hemiarthroplasty are available. In the case of our relatively young and active patient the excellent results justify our decision.

No benefits in any form have been received or will be received from a commercial party related directly or indirectly to the subject of this article.

\section{References}

1. Dorgan JA. Posterior dislocation of the shoulder. Am J Surg 1955;89:890-900.

2. Hawkins RJ, Neer CS 2nd, Pianta RM, Mendoza FX. Locked posterior dislocation of the shoulder. J Bone Joint Surg [Am] 1987;69-A:9-18.

3. Heller KD, Forst J, Forst R. Differential therapy of traumatically-induced persistent posterior shoulder dislocation: a review of literature. Unfallchirurg 1995;98:6-12 (in German)

4. McLaughlin HL. Posterior dislocation of the shoulder. J Bone Joint Surg [Am] 1952;24-A:584-90.

5. Cicak N. Posterior dislocation of the shoulder. J Bone Joint Surg [Br]2004;86-B:32432.

6. Constant CR, Murley AH. A clinical method of functional assessment of the shoulder. Clin Orthop 1987;214:160-4.

7. Hatzis N, Kaar TK, Wirth MA, Rockwood CA Jr. The often overlooked posterior dislocation of the shoulder. Tex Med 2001;97:62-7.

8. Jones TP, Beckenbaugh JP, Sperling JW, Amrami KK, Sundaram M. Your diagnosis?: posterior dislocation. Orthopaedics 2003;26:682, 745-6.

9. Schultz TJ, Jacobs B, Patterson RL. Unrecognized dislocations of the shoulder. J Trauma 1969;9:1009-23.

10. Buhler M, Gerber C. Shoulder instability related to epileptic seizures. J Shoulder Elbow Surg 2002;11:339-44.

11. Ryan J, Whitten M. Bilateral locked posterior shoulder dislocation in a footballer. $\mathrm{Br}$ J Sport Med 1997;31:74-5.

12. Matsen FA, Thomas SC, Rockwood CA, Wirth MA. Glenohumeral instability. In: Rockwood CA, Matsen FA, eds. The shoulder. Vol 2. Philadelphia, etc: WB Saunders Company, 1998:611-754

13. Rowe C, Zarins B. Chronic unreduced dislocation of the shoulder. J Bone Joint Surg [Am] 1982;64-A:494-505

14. Bloom MH, Obata WG. Diagnosis of posterior dislocation of the shoulder with use of Velpeau axillary and angle-up roentgenographic views. J Bone Joint Surg [Am] 1967;49-A:943-9

15. Wallace WA, Hellier $\mathbf{M}$. Improving radiographs of the injured shoulder. Radiography 1983;49:229-33.

16. Aparicio G, Calvo E, Bonilla L, Espejo L, Box R. Neglected traumatic posterior dislocations of the shoulder: controversies on indications for treatment and new CT findings. J Orthop Sci 2000;5:37-42. 
17. Spencer EE Jr, Brems JJ. A simple technique for management of locked posterior shoulder dislocations: report of two cases. J Shoulder Elbow Surg 2005;14:650-2.

18. Connor PM, Boatright JR, D'Alessandro DF. Posterior fracture-dislocation of the shoulder: treatment with acute osteochondral grafting. J Shoulder Elbow Surg 1997;6:480-5.

19. Gerber C, Werner CM, Vienne P. Internal fixation of complex fractures of the proximal humerus. J Bone Joint Surg [Br] 2004;86-B:848-55.
20. Loebenberg MI, Cuomo F. The treatment of chronic anterior and posterior dislocations of the glenohumeral joint and associated articular surface. Orthop Clin North Am 2000:31:23-34.

21. Page AE, Meinhard BP, Schulz E, Toledano B. Bilateral posterior fracture-dislocation of the shoulders: management by bilateral shoulder hemiarthroplasties. $J$ Orthop Trauma 1995;9:526-9.

22. Levy 0, Copeland SA. Cementless surface replacement arthroplasty of the shoulder: 5- to 10 -year results with the Copeland mark-2 prosthesis. J Bone Joint Surg [Br] 2001:83-B:213-21. 